\title{
Arte têxtil e química: transformadores da realidade
}

1. A produção de artigos têxteis é milenária. De facto têm sido efectuados achados arqueológicos em diversos pontos da Terra, desde o norte da Escandinávia à América do Sul, ao Vale do Nilo e também na Europa, que evidenciam o conhecimento da tecelagem de teia e trama desde há 9000 anos, ou ainda em épocas mais recuadas. As técnicas de tecelagem e os materiais usados são curiosamente semelhantes: um sistema de fios paralelos (a teia) é entrecruzada perpendicularmente com outro sistema de fios paralelos (a trama) com a ajuda de paus ou armaçðes no chão e mais tarde verticalmente. Os fios são de matérias vegetais lenhosas ou de pêlos de animais (lã). A tecelagem será nesses tempos recuados um produto do engenho do homem desenvolvido como resposta a necessidades objectivas de protecção. E desde então a produção de tecidos nunca mais deixou de estar ligada às várias funçðes pragmáticas que os têxteis têm desempenhado ao longo da história da humanidade, nas suas diversas épocas e culturas e nas mais diferenciadas circunstâncias climáticas e localizações geográficas. É assim que os têxteis com decoração dita artística não podem nunca ser dissociados da sua função pragmática. $\mathrm{Na}$ arte têxtil existe sempre uma relação profunda entre os elementos estéti$\cos$ e a função a que o objecto têxtil se destina.

A arte têxtil está portanto desde a sua origem comprometida indissoluvelmente com as técnicas de produção e as possibilidades que estas vão oferecendo. Durante milénios só existiram tecidos na cor natural das fibras de que eram feitos sendo o uso da cor relativamente recente em termos da história da humanidade.

No Egipto encontraram-se tecidos com partes coloridas do ano 2500 a.C. e na civilização lacustre da Suiça fizeram-se alguns achados de tecidos tintos. Mas também as civilizaçð̃es Mesopotâneas têm os seus tecidos de cor, tintos quer com plantas quer com produtos animais. Na Bíblia encontram-se numerosas referências a tecidos de cor «púrpura violeta», «púrpura escarlate», "carmesim», "vermelha» e «azul».

Mas também na Índia e na América do Sul, embora muito mais tardiamente, se tingiam tecidos utilizando como corantes substâncias extraídas de plantas e de animais.

Assim a cor amarela era dada por uma amora persa, o escarlate pelo insecto Kermes ilicis, o púrpura pelo molusco Murex, o azul pelas folhas do Isatis tinctoria ou do Indigo, existindo uma enorme variedade de plantas usadas para dar cor aos tecidos. Também algumas substâncias minerais são empregues como matérias corantes principalmente para obter o preto, o amarelo e cores escuras.

A aplicação de corantes naturais não era uma tarefa fácil antes necessitava de muita experiência, quer na procura e selecção das matérias adequadas, quer no seu tratamento, quer na sua aplicação. Algumas, como o Murex oriundo das costas da Fenícia, ou o indigo da Índia, atingiam preços elevadíssimos pela dificuldade de obtenção e qualidade das cores que produziam.

As substâncias corantes deveriam ser solúveis em água, no que se distinguiam dos pigmentos, para penetrarem nas fibras têxteis e nelas se fixarem. Esta fixação é de facto decisiva (ainda hoje) para a qualidade e durabilidade do tingimento. Para melhorar a fixação desenvolveram-se técnicas de mordentagem, usando cinzas, urina e sais minerais conforme c corante e a matéria têxtil em tingimento. De facto hoje sabe-se que a técnica de mordentagem consiste numa ligação iónica entre a fibra e o corante, resultando uma boa solidez de cor obtida, quer à luz quer à lavagem.

Nas civilizaçð̃es orientais onde a arte têxtil mais cedo floresceu, logo se desenvolveu a profissão de tintureiro que na Europa, durante a Idade Média, viria a adquirir verdadeira força social, agrupando-se os tintureiros em associaçðes conforme o tipo de matérias corantes e as técnicas usadas.

Havia os tintureiros só de preto, (o preto não era sinal de luto mas sim de luxo), os de "arte elevada", que tingiam as cores mais difíceis e caras e os de "arte baixa» que só retingiam peças de vestuário usadas.

Mas a arte dos tecidos cedo conheceu caminhos principalmente desenvolvidos na China e na Índia: a arte das sedas pintadas na China, a arte dos algodðes impressos na Índia.

Os tecidos decorados por estes métodos atingiam os mercados europeus a preços exorbitantes durante a Ic̉ade Média, o mesmo acontecendo a outro tipo de tecidos: os brocados e os damascos cuja decoração é produzida pela arte da tecelagem usando fios previamente tintos e mesmo fios metálicos de ouro e prata. As sedas chinesas chegavam a Veneza, a Constantinopla ou a Moscovo, em caravanas de camelos e cavalos pela chamada «Rota da Seda», longuíssimo trajecto desde o extremo oriental da China até ao Mediterrâneo, através da Ásia Central. A morosidade e os acidentes do percurso tornavam as sedas ainda mais raras e caras para os Europeus em cujas Cortes e Casas Nobres elas se tornavam indispensáveis.

Assim vários viajantes ocidentais, procuraram informaçðes sobre a seda e a sua produção, mas foram dois monges, agindo como espiðes para o Imperador Justiniano de Constantinopla que no ano 550 d.C. trouxeram alguns casulos de Bombix Mori escondidos nos seus bordðes de bambu. Daí nasceu a produção da seda em Itália e mais tarde na Provença.

\footnotetext{
a Engenheiro Têxtil, Professor na Escola António Arroio e no IADE (Instituto de Arte e Decoração).
} 


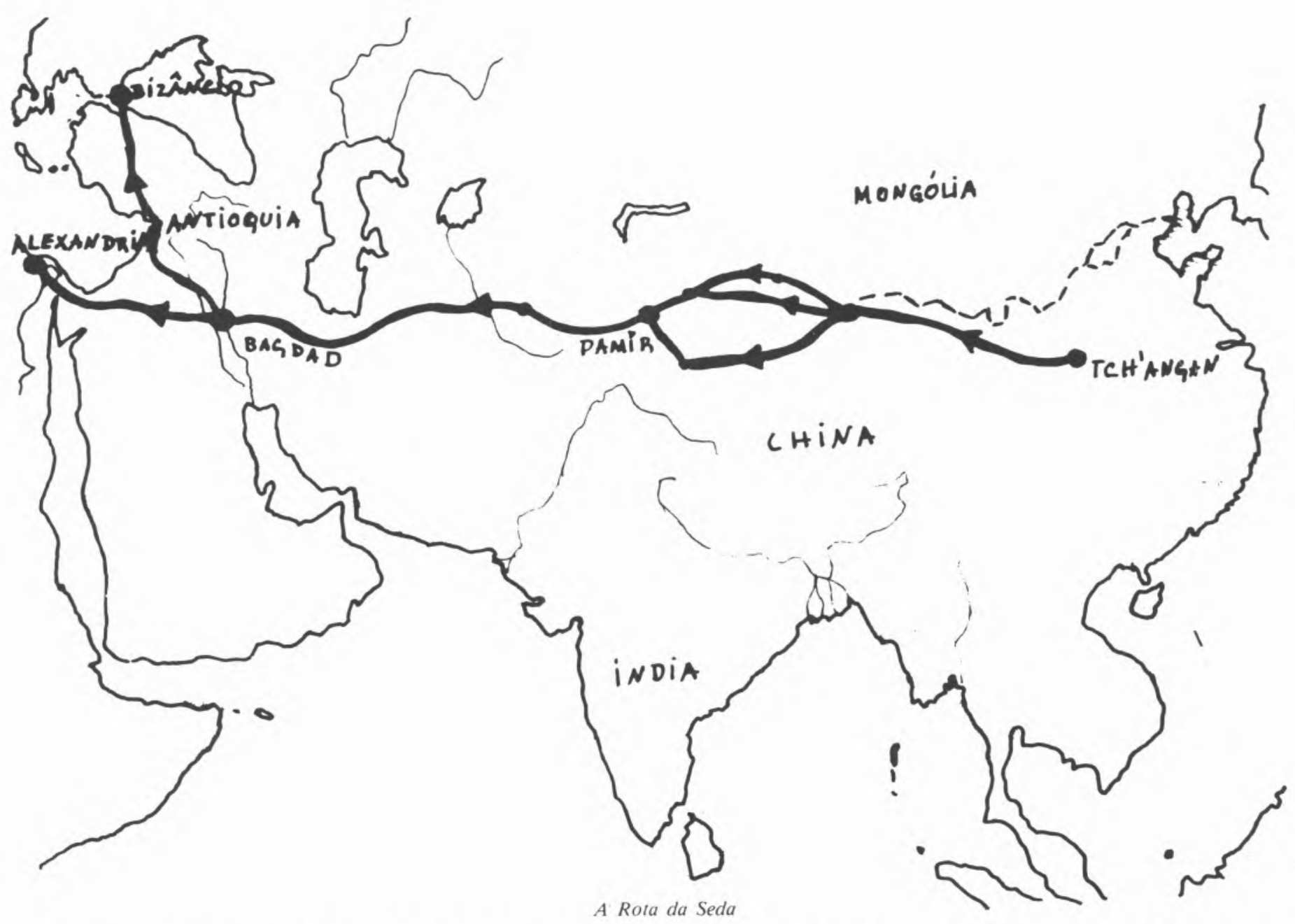

Curiosamente foi também nessa época que a seda chegou ao Japão, terminando assim o segredo imperial chinês do seu cultivo, que durara mais de 20 séculos e fizera a riqueza de tantas dinastias!

A técnica dos algodðes impressos na Índia espalha-se também pelo norte de África e pela Europa durante a baixa Idade Média, usando-se então gravuras planas de madeira, com o desenho a estampar em alto relevo, constituindo placas a que se chama "estampilhas» ou «blocos». Aos blocos planos gravados sucedem-se os rolos de madeira que permitem a impressão de desenhos contínuos e que provavelmente são de invenção árabe, durante o século XVI ou XVII. É posteriormente usada a técnica da gravura metálica plana, aberta a ácido e, já no começo do século XX, adopta-se como mais rigorosa e económica, a técnica «silk-screen» para a estampagem de tecidos.

Entretanto a arte dos tecidos evolui através de estilos e modas, geralmente importados do oriente mas logo transformados e adaptados ao gosto ocidental e às diferentes correntes artísticas que, desde a Idade Média aos nossos dias, foram construindo e caracterizando a cultura europeia.

Por seu lado os tecidos com desenhos produzidos pelo debuxo, isto é pelo diferente entrecruzamento dos fios, encontra no tear Jacquard (1801) o culminar de toda uma lentíssima evolução desde o tear chinês primitivo, passando pelo tear de licetas medieval europeu, usado em Itália e em Lyon (França). O tear Jacquard, comandando o levantamento individual dos fios da teia através duma cadeia de cartð̌es perfurados, colocada no al- to do tear, é a máquina que, a par da fiação mecânica (Jenny) de James Hardgreaves em 1764 e do tear mecânico de Edmund Cartwright patenteado em 1785 e 1786, fazem da produção de têxteis um dos pilares da transformação social e económica a que se chama a primeira revolução industrial.

São de facto inventos mecânicos deste tipo que produzem o arranque inicial para que a sociedade moderna se possa desenvolver, acelerando a produção e baixando o preço unitário do tecido e possibilitando o uso de têxteis de qualidade por um número cada vez maior de indivíduos.

2. Este rápido esboço da evolução da Arte Têxtil teve por fim perspectivar um conjunto de questðes que inevitavelmente se colocam ao considerarmos, a uma luz contemporânea, as relaçð̌es entre dois ramos do saber que cada vez mais se tornam complementares: a arte e a ciência quando encarados numa óptica de pesquisa, de inovação e de transformação social.

Se é certo que durante milénios se teceu manualmente e se tingiu usando exclusivamente matérias naturais, também é certo que a aceleração da investigação científica dos últimos 130 anos alargou anormalmente, não só as possibilidades criadoras na produção têxtil, como contribuiu para modificar o nosso modo de relacionamento com os objectos têxteis que, dia a dia, nos rodeiam e envolvem, em casa, no trabalho, no desporto, em todas as formas de vestir e de convívio social. 
Tais modificaçðes são tão profundas que hoje poderemos verificar que a nossa percepção das cores e a nossa concepção de utilização dos tecidos foi e é, dia a dia, profundamente influenciada pela relação entre o mundo da Arte Têxtil e da Ciência Têxtil.

As áreas da química da cor e de tinturaria, assim como a invenção e produção de fibras têxteis não-naturais, são dois campos privilegiados, para a investigação sociocultural dessas modificaçðes. Neste artigo, no entanto, apenas nos referiremos aos aspectos relacionados com os fenómenos da cor, mas sem entrar nos seus aspectos fisiológicos, psicológicos e simbólicos.

3. Falar da cor é abordar um assunto muito controverso, se desejarmos penetrar nas teorias filosóficas que, desde Aristóteles e passando por Goethe, tentaram explicá-la. (Aristóteles que no entanto só distinguia três cores simples: o branco, o amarelo e o preto!...). Se Aristóteles explicava a cor como resultado de transição entre o claro e o escuro, já Goethe perfilhando a mesma teoria, juntava-lhe uma componente emocional e subjectiva que ele próprio explicitava com o auxílio de numerosas experiências.

Para Newton (1665) a decomposição da luz branca solar em várias luzes coloridas, através dum prisma de cristal, era a prova de que a cor se relacionava com al-
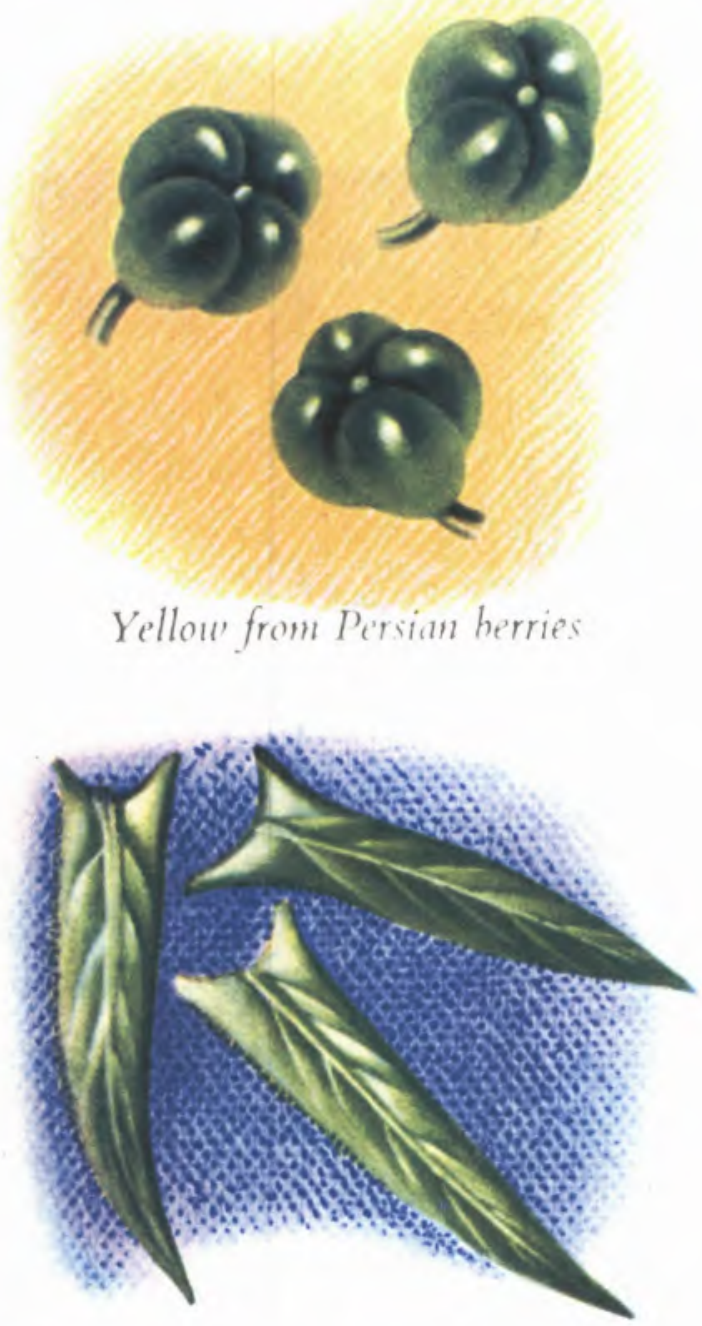

Blue from the leaves of woad (Isatis tinctoria) guma propriedade dessa mesma luz. Os raios de luz, nas palavras de Newton tantas vezes esquecidas, «não são elos próprios coloridos, mas apenas portadores da capacidade de produzirem em nós a sensação correspondente a uma cor".

Mais tarde, em 1727, a teoria ondulatória de Thomas Young permitiria afirmar que a propriedade a que Newton se referia é o comprimento de onda, podendo associar-se um certo comprimento de onda a uma certa sensação colorida.

Assim, se estabeleceu o espectro solar, tal como nós hoje o concebemos:

\begin{tabular}{|c|l|}
\hline Comprimento de onda em nanómetro & Cores \\
\hline $800-650$ & vermelho \\
$640-590$ & laranja \\
$580-550$ & amarelo \\
$540-490$ & verde \\
$480-460$ & azul \\
$450-440$ & anil \\
$430-390$ & violeta \\
\hline
\end{tabular}

Mas tal distribuição é subjectiva, pois os limites entre as cores podem ser percebidos e estabelecidos de modo diferente e fixados entre outros comprimentos de onda.
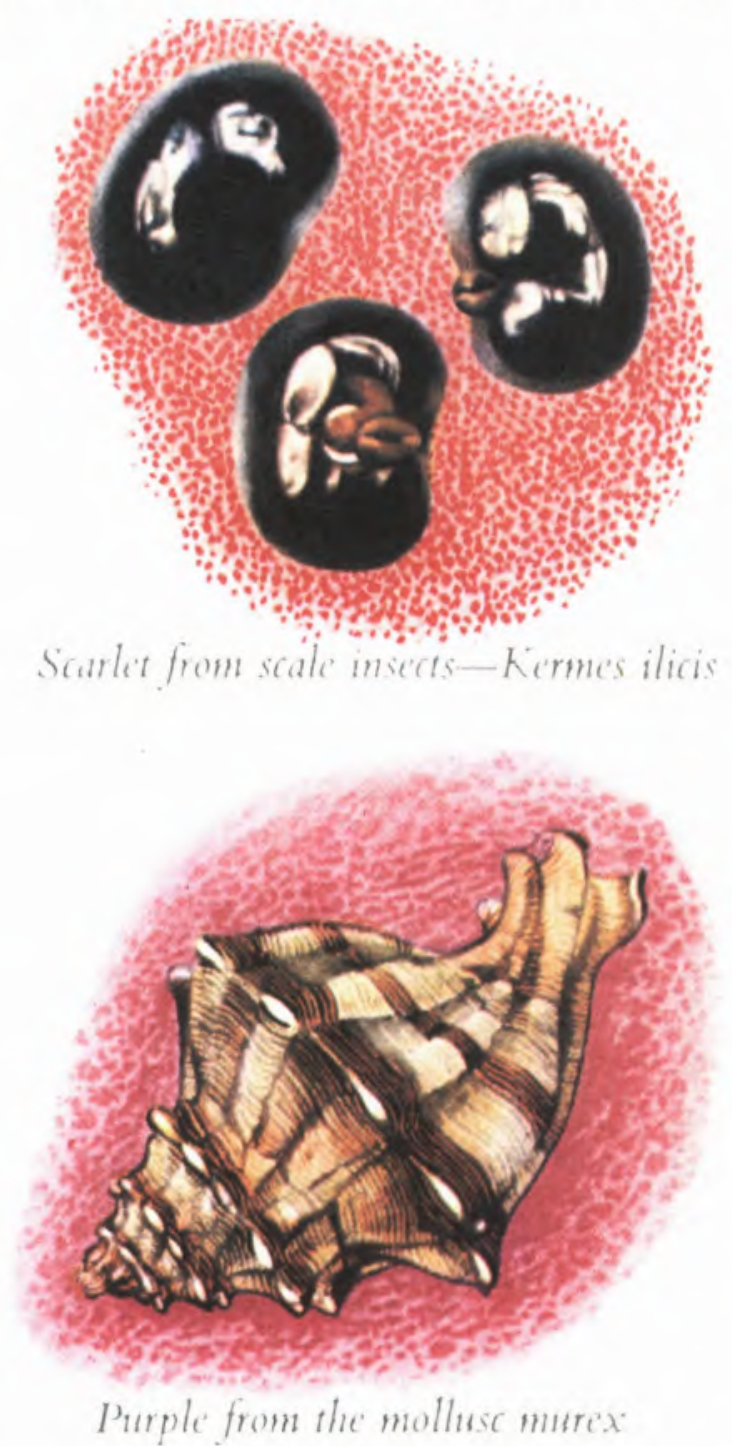
Por outro lado, a percepção das cores é condicionada tanto individual como cultural e colectivamente.

A percepção que hoje temos das cores é condicionada pelos estímulos culturais que a nossa sociedade nos dá e estes dependem, por seu turno, das possibilidades de produção de objectos coloridos que a ciência e a tecnologia nos possibilitam.

Quando, em 1856, o jovem investigador químico inglês William Henry Perkin, ao tentar sintetizar o quinino a partir do benzeno, obteve uma substância negro-acastanhada que se viria a transformar no primeiro corante sintetizado, estava dando o primeiro passo para a criação duma poderosa nova indústria, mas também para a formação da sensibilidade colorística moderna, que viria a caracterizar o século XX (até à recente invenção da televisão a cores). De facto, foi dessa descoberta de Perkin (a Mauveina), que resultou a primeira gama de corantes sintéticos, a que outros se seguiram, primeiro na Inglaterra e depois na Alemanha, que tomou rapidamente a liderança da nova e próspera indústria.

Entre as primeira descobertas deve referir-se a dos corantes azóicos e dos primeiros corantes ácidos para a lã.

Hoje existem várias famílias de corantes sintéticos, tendo-se constituído todo um ramo da Química que a eles se dedica, no sentido de obter melhores características, quer na aplicação durante a tinturaria, quer no uso dos objectos têxteis depois de tintos.

TIPOS DE CORANTES E SUAS APLICAÇÕES ÀS DIFERENTES FIBRAS TÊXTEIS

\begin{tabular}{|c|c|c|c|c|c|c|}
\hline $\begin{array}{r}\text { Tipo de } \\
\text { fibra } \\
\text { po }\end{array}$ & $\begin{array}{c}\text { Proteinica } \\
\text { (lã, } \\
\text { (seda) }\end{array}$ & $\begin{array}{c}\text { Celulósica } \\
\text { (algodåo. } \\
\text { viscose } \\
\text { modal) }\end{array}$ & $\begin{array}{c}\text { Acetato } \\
\text { e } \\
\text { Triacetato }\end{array}$ & Poliamida & Poliester & Acrilica \\
\hline Ácido & XX & - & - & $\mathrm{XX}$ & - & - \\
\hline $\begin{array}{l}\text { Azóico } \\
\text { Básico }\end{array}$ & - & $X X$ & $\mathrm{X}$ & $\mathrm{X}$ & $X$ & $\mathrm{X}$ \\
\hline (ou catiónico) & - & - & - & - & - & $\mathrm{XX}$ \\
\hline $\begin{array}{l}\text { de Cuba } \\
\text { de Cuba }\end{array}$ & $\mathrm{X}$ & $\mathrm{XX}$ & - & - & - & - \\
\hline solubilizado & $\mathrm{X}$ & $\mathrm{XX}$ & - & - & $\mathrm{x}$ & - \\
\hline Directo & $\mathrm{X}$ & $x x$ & - & $\mathrm{X}$ & - & - \\
\hline Disperso & - & - & $\mathrm{XX}$ & $\mathrm{XX}$ & $\mathrm{XX}$ & $\mathrm{XX}$ \\
\hline Ftalocianina & - & $\mathrm{XX}$ & - & - & - & - \\
\hline Metalifero & $\mathrm{XX}$ & - & - & $\mathrm{XX}$ & - & - \\
\hline a Mordente & $\mathrm{XX}$ & - & - & - & $x$ & - \\
\hline de Oxidação & - & $\mathrm{X}$ & - & - & - & - \\
\hline Pigmento (*) & $\mathrm{X}$ & $\mathrm{X}$ & $\mathrm{x}$ & $\mathrm{x}$ & $\mathrm{X}$ & \\
\hline Reactivo & $\mathrm{XX}$ & $X X$ & - & $\mathrm{x}$ & - & - \\
\hline Sulfuroso & - & $x X$ & - & - & - & - \\
\hline
\end{tabular}

XX Muito adequado; X Adequado em certos casos; ( $\left.{ }^{\bullet}\right)$ Não pode ser considerado um verdadeiro corante.

in «Manual de Engenharia Têxtil», 2. ${ }^{\circ}$ vol. Mário de Araújo e E.M. de Melo e Castro.

Embora não possamos saber qual era a visão colorística da pré-história, da Antiguidade, da Idade Média ou do Renascimento, é-nos no entanto possível considerar que, desde a descoberta de Perkin, se deu um dramático alargamento das possibilidades de percepção das cores, agora produzidas sinteticamente, sem limitaçð̄es de matiz, de intensidade, de claro/escuro (tom) e da sua reprodução rigorosa em objectos feitos à escala industrial.

Na Pré-História e na Antiguidade a percepção colorística estava limitada às cores da natureza o que, no caso dos têxteis, se reduzia a beijes e castanhos. Nas civilizaçð̃es Mesopotâmicas as cores púrpura, violeta, escarlate, azul, carmesim são frequentemente referidas, mas não podemos saber exactamente a que sensaçðes colorísticas os autores antigos se referiam.

O problema é tanto mais complexo quanto os nomes das cores não estavam perfeitamente em concordância com as sensaçðes descritas e variavam de civilização para civilização. Umberto Eco refere que o autor latino Aulus Gellius observa que em latim, vermelho (rufus) e verde (viridis), são apenas dois nomes, mas têm muitas variedades. Assim «rufus» é um nome, mas que diferença entre o vermelho do sangue, da púrpura, do açafrão ou do ouro!....

E os exemplos podem multiplicar-se, quanto à imprecisão da terminologia da cor em latim. Por exemplo, no mesmo texto de Fronto, «Flavus» (uma cor) é descrita sucessivamente como sendo uma mistura de verde e branco; verde, vermelho e branco; e finalmente uma sucessão de vários tons de vermelho!

De facto, citando ainda Umberto Eco: «... somos confrontados com termos para designar cores, mas não sabemos a que efeitos cromáticos se referem. Conhecemos bem a escultura e arquitectura Romana mas muito pouco sobre a sua pintura. As cores que hoje vemos em Pompeia não são as cores que os pompeianos viam; mesmo que os pigmentos sejam os mesmos, as respostas cromáticas não o são.

No séc. XIX Gladstone sugeriu que os Gregos eram incapazes de distinguir o azul do amarelo. Goetz e outros autores, admitiram que os romanos não distinguiam o azul do verde... Os Egípcios usavam azul nas

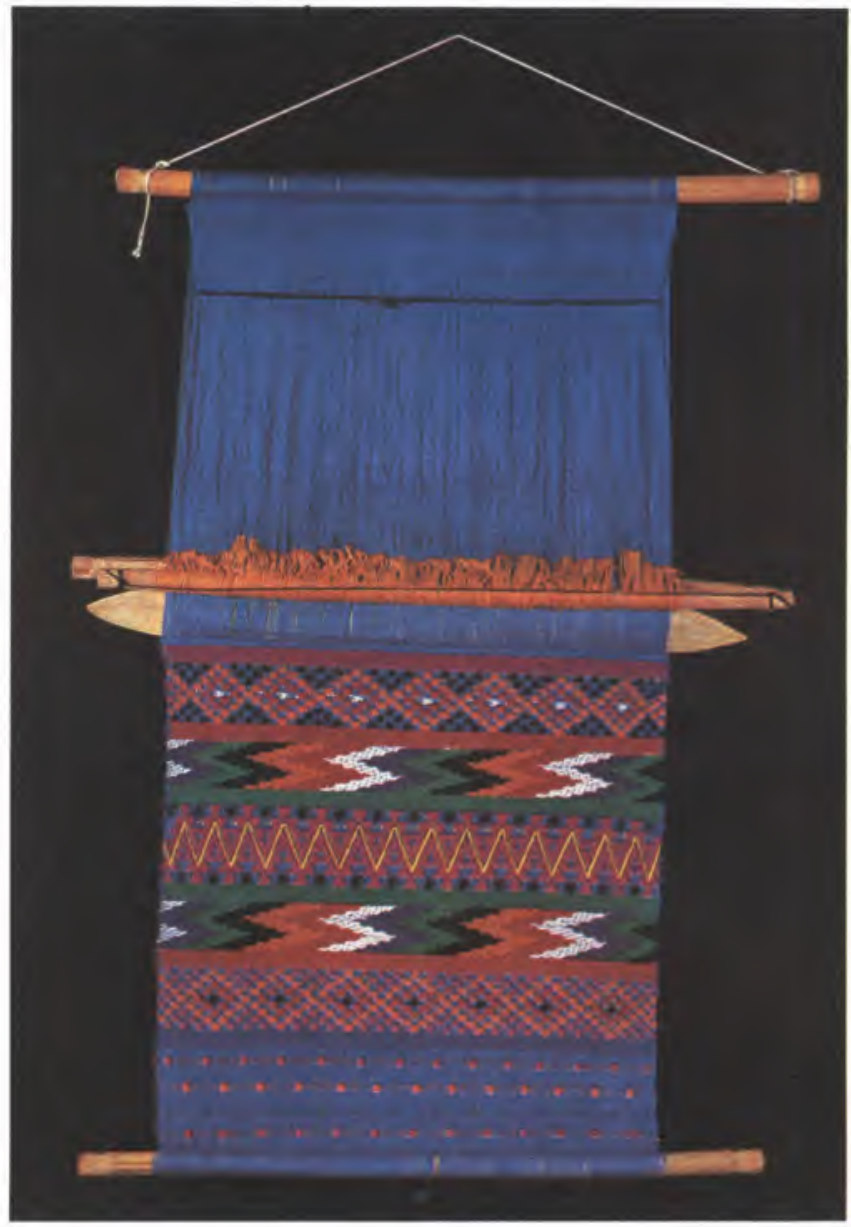

Pequeno tear manual com efeitos obtidos com fios tintos em cores vivas usando corantes sintéticos. $O$ artesanato também se modificou sob o impacto das novas possiblidades colorísticas. 
pinturas mas não possuiam termo para o designar e os Assirios para designarem azul referiam-se a lapis lazuli adjectivando-o (UKNU).»

Por seu lado para os Indus o vermelho e o laranja são um só, enquanto os Maori da Nova Zelândia têm 3000 termos diferentes para designar 3000 diferentes matizes!

$\mathrm{Na}$ Idade Média as cores usadas nos têxteis limitavam-se quase exclusivamente ao vermelho, ao verde, ao azul e ao preto, mas os tintureiros sabiam como obter uma vasta variedade de tonalidades com poucos corantes (vegetais ou animais) usando também a mistura com outros vegetais, como flores e ervas secas ou raízes.

Na Renascença, Leonardo da Vinci refere apenas quatro cores simples, além do branco e do preto: amarelo, verde, azul e vermelho.

Para nós, colocados quase no final do século $\mathrm{XX}$, é dificil conceber tais limitaçðes colorísticas e custa-nos a crer que até final do séc. XIX os ‘têxteis eram apenas tintos com corantes naturais! Isto, quando a nossa sensibilidade colorística já está sendo modificada por cores geradas electronicamente no vídeo e na televisão! Facto cultural este que decerto vai alterar a nossa visão do mundo e a nossa própria aptidão para falar da cor e para manifestar as nossas preferências.

As constantes e periódicas variaçðes das cores da moda podem e devem ser actualmente consideradas a esta luz, visto que não há hoje limites ao que em termos de cor se pode produzir e reproduzir num suporte têxtil. Existem actualmente vários índices de cores que registam e indiciam rigorosamente uma enorme quantidade de cores. Por exemplo, a Sociedade Óptica Americana classifica uma gama entre 7,5 a 10 milhøes de cores que podem ser teoricamente descriminadas.

Neste caso coloca-se o problema de saber até que ponto a percepção humana pode distinguir essas cores e, caso sejamos capazes de as distinguir visualmente, como nos referiremos verbalmente a essas pequeníssimas e subtis diferenças de matiz e de tonalidade? No máximo, em inglês são registados 3000 termos relativos à cor (Maerz e Paul) mas apenas 8 são de uso corrente! Em português, pensamos que um estudo linguístico da terminologia da cor está ainda por fazer. Um artista pintor pode certamente distinguir muitos mais matizes que uma pessoa sem treino colorístico, 0 mesmo acontecendo com os técnicos dos laboratórios produtores de tintas e corantes. No entanto o problema subsiste, entre a discriminação e a categorização das sensaçð̄es coloridas.

$\mathrm{Na}$ sociedade actual o desenvolvimento da química dos corantes tem agudizado esta questão, estando nós, hoje, numa posição conceptual muito semelhante à dos romanos: a terminologia da cor é para o homem comum confusa e ambígua, eivada de imprecisð̄es, sendo reflexo muitas vezes de conflitos emocionais, entre estímulos excessivos vindos duma realidade em rápida transformação e a incapacidade de categorização e expressão desses novos e múltiplos estímulos.

No campo científico e tecnológico a colorimetria e a informatização da tinturaria já resolveram esse problema. A colorimetria adoptou um sistema de parâmetros referenciais, em termos das cores ditas primárias e ainda um factor de luminância.

De acordo com a teoria aditiva, estudada por Grassmann, todas as cores são o resultado da adição de dois ou três estimulos luminosos, chamados primários. Uma vez conhecidos os seus comprimentos de onda é possível traçar uma curva num sistema de coordenadas que contenha todas as cores. É a curva de Maxwell. Esta curva tem a forma de um triângulo com 2 lados e um vértice curvos e é traçada em referência a um ponto central, o iluminante $C$, que define os factores de claridade e pureza.

Com um espectofotómetro de três estímulos podem assim determinar-se os parâmetros definidores de cada cor, facto este que vai permitir a informatização da tinturaria dos têxteis. De facto, com a ajuda do computador, determina-se a mistura percentual dos corantes a usar para o tingimento rigoroso de qualquer cor, sobre qualquer material têxtil, usando determinada maquinaria de tinturaria. Assim se elimina o factor subjectivo na apreciação e reprodução da cor, a nível industrial. Mas para todos nós, utentes da cor, o problema subsiste e agudiza-se. À nossa volta a realidade transforma-se. As cores novas que se sucedem, cada vez mais rapidamente, impulsionadas pela moda e pelo marketing dos têxteis, tendem a confundir as nossas referências culturais e a tornarem obsoleto aquilo a que nos habituámos a chamar o gosto, o «nosso bom gosto».

Tal categoria estética quase não tem hoje mais razão de ser, pois nem já os artistas sabem onde está o bom ou o mau gosto. A escola de pintura conhecida por «bad painting» é mesmo disso um exemplo internacional.

Às noçð̄es estéticas do passado somos assim levados a opor novas categorias de apreciação, mais adequadas à cultura deste fim de século. Lembremo-nos, por exemplo, da oposição entre harmonia e contraste, ou entre continuidade e inovação. As noçð̃es de harmonia e contraste são, na moderna teoria de cor, conceitos que se definem independentemente da apreciação subjectiva. De facto, fala-se em contraste quando duas ou mais cores que não estão seguidas no espectro solar, são colocadas lado a lado. O efeito é forte e impressiona vivamente. Se combinarmos cores seguidas do espectro solar, ou no conjunto, incluirmos tonalidades (branco, cinza, preto), o resultado é harmónico.

Estes dois conceitos, quando usados alternadamente, têm importância decisiva na determinação da Moda têxtil, importância que aumenta quando associados a outro par de ideias contrárias, a continuidade e a inovação. Agora, são consideraçōes sociologicas que levarão a ligar a continuidade à preferência pelas harmonias e a inovação a procurar os contrastes.

Inovação e constraste ligados a grupos jovens; continuidade e harmonia, como predominantes em grupos sociais conservadores, de nível etário mais elevado.

Mas toda esta coerência, pode ser subvertida pela intervenção dum factor psico-social: a saturação que pode provocar a inversão das tendências de moda, levando os jovens a preferir harmonias, enquanto os individuos na idade adulta optem pelos contrastes!

Com uma conceituação deste tipo talvez possamos conceber um novo sistema socio-estético que nos ajude a entender os estímulos colorísticos da nova realidade em que os têxteis e a química desempenham um decisivo papel transformador. 